\title{
Acoustic Doppler Current Profiler observations in the southern Caspian Sea: shelf currents and flow field off Feridoonkenar Bay, Iran
}

\author{
P. Ghaffari ${ }^{1,2}$ and V. Chegini ${ }^{3}$ \\ ${ }^{1}$ Department of Geosciences, University of Oslo, P.O. Box 1022, Blindern, 0315, Oslo, Norway \\ ${ }^{2}$ Department of Physical Oceanography, Iranian National Center for Oceanography, Western Fatemi, 1411813389, \\ Tehran, Iran \\ ${ }^{3}$ Department of Marine Engineering, Iranian National Center for Oceanography, Western Fatemi, 1411813389, Tehran, Iran
}

Received: 3 October 2009 - Published in Ocean Sci. Discuss.: 8 December 2009

Revised: 2 July 2010 - Accepted: 16 July 2010 - Published: 22 July 2010

\begin{abstract}
The results of offshore bottom-mounted ADCP measurements and wind records carried out from August to September 2003 in the coastal waters off Feridoon-kenar Bay (FB) in the south Caspian Sea (CS) are examined in order to characterize the shelf motion, the steady current field and to determine the main driving forces of currents on the study area. Owing to closed basin and absence of the astronomical tide, the atmospheric forcing plays an important role in the flow field of the CS. The lasting regular sea breeze system is present almost throughout the year. This system performs the forcing in diurnal and semi-diurnal bands similar to tides in other regions. In general, current field in the continental shelf could be separated into two distinguishable schemes, which in cross-shelf direction is dominated by high frequencies ( $1 \mathrm{cpd}$ and higher frequencies), and in along-shelf orientation mostly proportional to lower frequencies in synoptic weather bands. Long-period wave currents, whose velocities are much greater than those of direct wind-induced currents, dominates the current field in the continental shelf off FB. The propagation of the latter could be described in terms of shore-controlled waves that are remotely generated and travel across the shelf in the southern CS. It has also been shown that long term displacements in this area follow the classic cyclonic, circulation pattern in the southern CS.
\end{abstract}

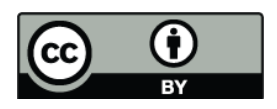

Correspondence to: P. Ghaffari (peygham.ghaffari@geo.uio.no)

\section{Introduction}

The Caspian Sea (CS) is the largest inland water body of the world with a surface area of $379000 \mathrm{~km}^{2}$, a drainage area of approximately 3.5 million $\mathrm{km}^{2}$, and a volume of $78000 \mathrm{~km}^{3}$ (Froehlich et al., 1999). This lake is located at Northern Hemisphere between latitudes of $36^{\circ}$ and $45^{\circ}$. An area with various bathymetric levels is rather originally distributed over the CS (Ismailova, 2004). Conventionally southern, central and northern basins are distinguished. The Southern and the central basins of the CS have maximum water depths of 1025 and $788 \mathrm{~m}$ respectively. These basins are separated by a sill with a maximum depth of about $170 \mathrm{~m}$ and the northern basin with maximum depth about $20 \mathrm{~m}$ is a very thin extension of the central basin (Peeters et al., 2000). The surface area of these three basins are more or less equal (ValiKhodjeini, 1994).

The southern basin of the CS has a subtropical climate characterized by warm summers and mild winters. MadatZade (1959) classified 13 atmospheric circulation patterns which determine the wind field over the CS, which latterly was stored into two groups. The first one includes those patterns that are characterized by strong northerly winds. Almost half of the winds belong to the northwestern quarter. The second group comprises atmospheric circulation patterns with strong southerly wind (Rodionov, 1994). The role of the atmospheric circulation is fundamental in formation of the Caspian hydro-meteorological regime due to the lack of the outlet.

The process of hydrological fields transformation, redistribution of biogenic and pollutant substances depends significantly on horizontal circulation of the CS, which have not been studied enough (Ismailova, 2004). Main circulations

Published by Copernicus Publications on behalf of the European Geosciences Union. 
in the CS consist of cyclonic eddies (Terziev et al., 1992) and mesoscale eddy features which have seasonal evolution (Trukhchev et al., 1995). The CS currents are considered to be mainly wind-generated. Other types of currents, e.g. baroclinic currents and seiches also play important roles in local circulation patterns (Sur et al., 2000). Over the central basin of the CS, the main features of circulation are a cyclonic gyre, a jet-like current in the cyclonic sense along the western and eastern boundaries, and an anti-cyclonic gyre in south of the Apsheron Peninsula/Azerbaijan (Korotenko et al., 2000). Although various field measurements were carried out in the northern and the central basins of the CS (Bondarenko, 1993; Klevtsova, 1967; Kosarev, 1990; Tuzhilkin et al., 1997), only a few measurements have been accomplished in the southern basin in order to investigate the coastal flow field (Zaker et al., 2007).

A series of field measurements were carried out by Iranian National center for Oceanography in FB near the Mazandaran Province, Iran, using Acoustic Doppler Current Profiler (ADCP). The scope of this paper is to describe and interpret the results obtained from the analysis of the ADCP observations and wind data sets gathered from August to December 2003 in the southern part of the CS. The main subjects of the study were to characterize the shelf motion and steady current field, as well as determining the main driving force of currents within the study area. We tried to shed some light on the flow pattern of the selected area and explain some of the features encountered along the Iranian shelf. More specifically, these features are: the surface coastal currents which are strongly influenced by the local winds; the sea breeze system present throughout the year which acts similar to tide; and the flow regime, which exists along the southern coast exposed by remote forces (synoptic wind). In Sect. 2 of the present paper a brief description of the study area and the field measurement design is given; in Sect. 3, a description of the method used in the data analysis for the separation of the different components of currents can be found; in Sect. 4, the results obtained are shown and discussed and finally the conclusion has been presented in Sect. 5 .

\section{Field measurement}

\subsection{Study area}

The study area is located at the south-east part of the CS, which covers coastal waters of the Mazandaran Province (Fig. 1). Based on the topographic features, the continental shelf has an approximately $10 \mathrm{~km}$ width along almost the whole Iranian coast of the CS. From the coastline depth, increases gently to about $45 \mathrm{~m}$ (shelf break), thereafter it increases dramatically to $400 \mathrm{~m}$ in $18 \mathrm{~km}$ (Zaker et al., 2007). The continental shelf in the southern coastal areas is fairly narrow and topographic contours are parallel to the coastline

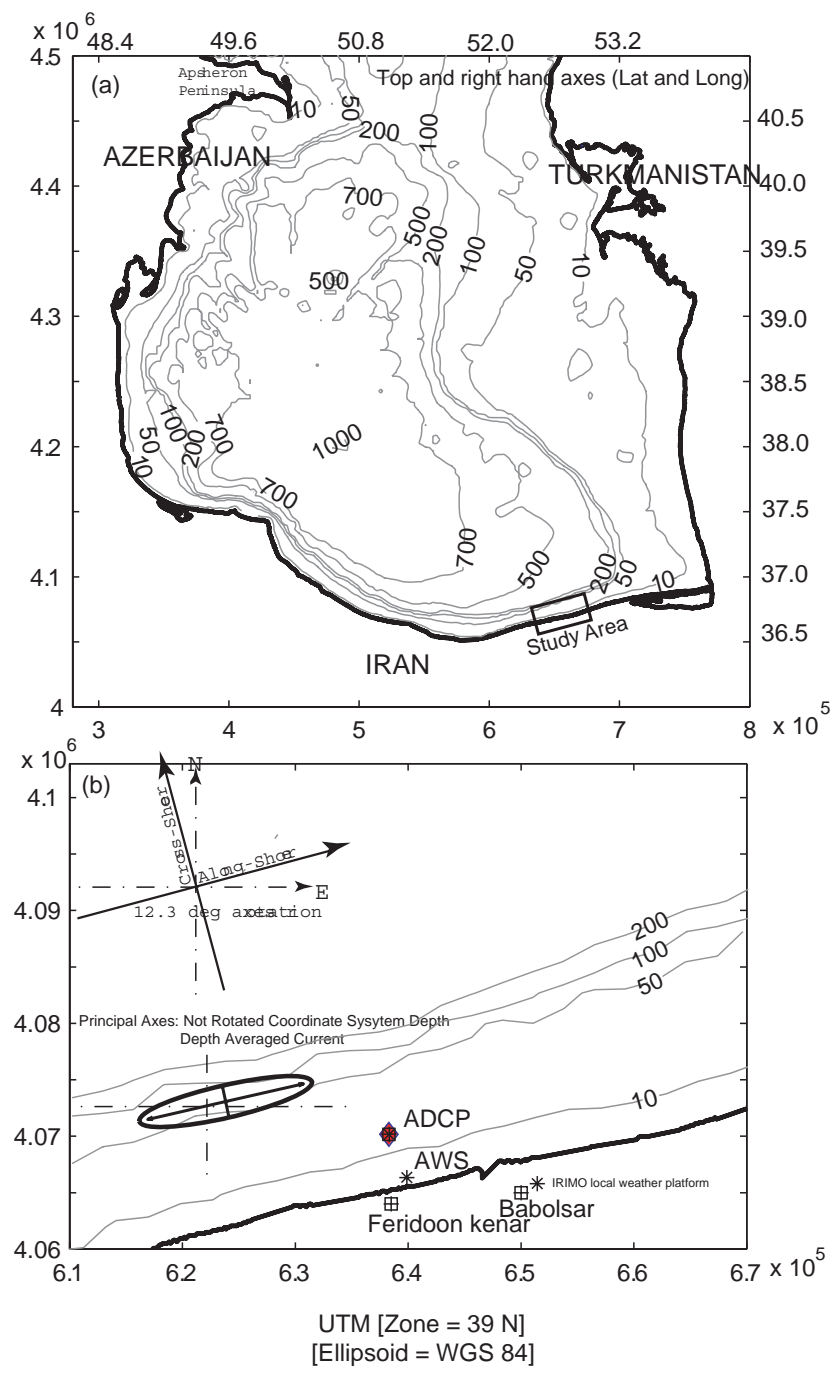

Fig. 1. Location map showing field sites.

and follow the same feature from west to the east side covering roughly $400 \mathrm{~km}$.

\subsection{Observations}

The coastal current and weather parameters observations were carried out using a combination of bottom-mounted $300 \mathrm{KHz}$ Acoustic Doppler Current Profiler (ADCP) and Automatic Weather Station (AWS 2700, AANDERAA). The ADCP ping rate was set to $0.25 \mathrm{~Hz}$, with 150 pings per 10min ensemble, and 12 depth bins (of $1 \mathrm{me}$ ) after $1 \mathrm{~m}$ blanking distance. This quasi-rapid sampling permitted detailed observation of the velocity structure of the area. The ADCP was deployed $4 \mathrm{~km}$ offshore of $\mathrm{FB}$, in the southeastern coastal waters of the $\mathrm{CS}$ at the 14 meter isobath $\left(36^{\circ} 43.284^{\prime} \mathrm{N}\right.$, $52^{\circ} 33.127^{\prime}$ E) for 57 days from August 2003 to September 2003 . 
Wind parameters were regularly recorded every $3 \mathrm{~h}$ by Iran Meteorological Organization (IRIMO). Considering the Babolsar Bay meteorological platform location (which belongs to IRIMO), recorded data could not completely be attributed to the study area. Additionally these measurements were based on old fashion and aged instruments (e.g. generally not self contained), and there were some doubts about the recordings accuracy. In order to obtain suitable data, an Automatic Weather Station (AWS), was installed at the head of the FB Jetty fairly adjacent to the study area and free from any obstruction which may affect the data quality. The meteorological parameters recording frequency was $6 \mathrm{cph}$ and observations were sustained for four months from early August to the end of November 2003. The regional depth contours and shoreline define an alongshore direction rotated $12.3^{\circ}$ anti-clockwise from east. Therefore alongshore (positive directed $77.7^{\circ} \mathrm{E}$ ) and cross-shore (positive oriented $347.7^{\circ} \mathrm{N}$ ) directions modification was applied to the current data.

\subsection{Data analysis}

\subsubsection{Data treatment}

Prior to conducting the analysis, both the original wind and current data were supplied as two components $(\mathrm{u}-$ positive eastward, v - positive northward). According to the coast orientation in the study area (Fig. 1b), the coordinate system was rotated $12.3^{\circ}$ anti-clockwise to define an alongshore and cross-shore components for currents. Principal axes for consecutive bins from bottom (bin 01) to surface (bin 12) and for the depth average current were calculated. The major and minor axes, orientation and ellipticity were computed from east (u), and north (v) current components in geographic (east/north), as well as rotated coordinate system. Figure $1 \mathrm{~b}$ shows the principal axes and current ellipses of original ADCP measured currents and along-shore; cross-shore current components were calculated considering $12.3 \mathrm{deg}$ anti-clockwise from east. A quality control procedure was performed to eliminate obvious errors. Then the data were checked for date, changes in references and clears spikes, i.e., anomalous values that may appear occasionally due to errors in target speed or on endpoints of data during instrument handling procedure.

The analysis revealed that the underlying distribution is not normal. The method of First Differences (FD) is useful to demonstrate if a data set is acting nearly linear or not. The FD method for combining station data (Peterson et al., 1998) was created to facilitate the use of short data segments in the analysis of surface data (Free et al., 2004). Therefore the current data spikes were individuated utilizing the FD method: the FD was determined from the primary set of current data to achieve a second-order stationary (mean and variance are steadier than the original data set). Up to specific degree, the differenced data satisfy condition of a normal distribution.
The FD series is the time series, so that

$D_{t}=x_{t}-x_{t-1}$,

where $x_{t}$ is the value of the variable at time $t$. The $D_{t}$ values for each time step were averaged over the 12 bins to form binaveraged a first difference series $r_{t}$. The mean time series was then constructed by cumulatively summing the bin-averaged first difference values from the first sample to the last, setting the first record to zero:

$R_{n}=\sum_{t=1}^{n} r_{t}$

Then, a threshold was defined at $\pm 3.0 \times$ std (std stand for standard deviation of first differences). Within this limit, $99 \%$ of $R_{n}$ time series is included. Hence all those data that fell outside of the $99 \%$ interval and those correspondence data in original time series were investigated as probable error spikes. The necessary requirement was: if one value was suspected and fell at the $0.5 \%$ extreme end of the distribution and then the neighboring value in time fell at the other $0.5 \%$ extreme end of the distribution, then the suspected value indicated as a spike that was eliminated from the original data set (Kovačvić et al., 2004). In such way, the anomalous values were removed. The cleaned time series, called de-spiked data, were the core of all further analysis. Then clean data were filtered to obtain the hourly data. The smooth hourly data facilitated by applying symmetrical filter, to the original de-spiked ( 6 cph sampling intervals) time series. The filtered value $X_{f}(t)$ at time $t$ is computed by the following formula:

$$
X_{f}(t)=F_{0} \times X(t)+\sum_{m=1}^{m} F_{m}[X(t+m)+X(t-m)]
$$

$m=27$

Considering the symmetrical nature of the filter, no phase shifts are introduced to the dataset (Pugh, 1987).

\subsubsection{Basic method for time-series analysis}

A power spectrum, obtained by a complex Fast Fourier Transform (FFT), is a tool for distributing the total variance over a range of frequencies. The highest frequency i.e., the Nyquist frequency, which can be resolved with a sampling interval of one hour, is $0.5 \mathrm{cph}$. The essential requirement for applying a classical FFT method is the continuity of the data record. Therefore, the time series of the current and wind components were inspected for gaps both initial $(6 \mathrm{cph}$ sampled data) and hourly filtered. When the gap size is small (not longer than $6 \mathrm{hr}$ ), it can be linearly interpolated (Kovačvić et al., 2004). The zero-padding method was used in the case of the only large gap (for ADCP time series during the battery change and data retrieval near the middle of the recording period). Although adding zeros helps the process of filling the shape of the spectrum, but in no case it improves the fundamental frequency resolution (Emery and Thomson, 
1998). Three bin layers were chosen to appraise spectral energy variation and time series analysis between different levels of water column.

Decomposition of a complex horizontal velocity vector, $\boldsymbol{w}(t)=u(t)+i v(t)$ into counter-rotating circularly polarized components can aid in the separation of the energy into positive and negative rotary frequencies. In rotary spectral analysis, the different frequency components of the vector $\boldsymbol{w}(t)$ are represented in terms of counterclockwise (positive angular frequency $w \leq 0$ ), and clockwise (negative angular frequency $w \geq 0$ ) rotating vectors. The method of the rotary analysis of current is particularly effective for identifying inertial motions. Inertial oscillations appear as a peak in the rotary spectrum in the clockwise rotary frequencies in the Northern Hemisphere and the anticlockwise component in the Southern Hemisphere after removing the tides from the rotary components (Pugh, 1987).

In order to relate the current to some particular wind conditions, the high-frequency current motions were eliminated by low-pass filtering. A digital symmetric low-pass filter (PL33) (Beardsley et al., 1985; Flagg et al., 1976), was applied to the time series (wind and current). Low-frequency currents were then used for mapping the hourly flow field in conjunction with some extreme wind conditions in order to illustrate the wind-forced low-frequency responses. The CS does not contain natural periods of resonance which align closely with either the diurnal or semi-diurnal tide rising forces. Hence it does not respond vigorously and consequently, no significant tide is generated. The tidal range does not exceed more than few centimeters in the CS and such small tides may often be invisible or masked by other phenomena such as wind. By applying harmonic analysis to the current data (not shown here), based on Forman (1978), and utilizing a number of MATLAB programs, it was found that tide does not have a substantial contribution in the flow field. Therefore it is trivial to remove the tidal component from data prior to further analysis which is usual in signal processing.

\section{Results and discussion}

\subsection{Wind variability}

Meteorological conditions over the CS and adjacent regions are determined by air circulation over the Eurasian continent, as well as by the coastal area relief. Meanwhile, the meteorological parameters change greatly over the territory of the CS (Filimonova and Trubetskova, 2005). In order to illustrate the local wind condition over the study area, hourly filtered wind data in some particular periods were selected. For this purpose, two time segments were chosen: first $720 \mathrm{~h}$ of hourly wind data (1-31, August 2003) owing to demonstrate sea breeze system, and last $740 \mathrm{~h}$ (24 October25 November 2003) of hourly wind which represents some events. Strong NW winds occurred sporadically during this recording period with relatively frequent events during the cold season, while notably fewer in the hot season. When local weather conditions are influenced by the passages of synoptic atmospheric perturbations, cyclones and anti-cyclones (Mofidi et al., 2008), both may provoke noticeable winds over the southern parts of the CS.

The wind stick plot, the wind magnitude and the wind stress of hourly wind data for the first and last segments are shown in Fig. 2. The maximum hourly speed of $18 \mathrm{~m} \mathrm{~s}^{-1}$ is recorded on 15 November 2003. August 2003, is characterized by relatively stable weather conditions with very few episodes of strong winds, which do not exceed $15 \mathrm{~m} \mathrm{~s}^{-1}$ as an hourly value. Contrary to August, in September 2003, the weather conditions are characterized by relatively highly variable winds in terms of frequency and duration. North and northwesterly winds are more evident, but still the sea breeze system is dominant and the maximum hourly speed does not exceed $15 \mathrm{~m} \mathrm{~s}^{-1}$ in the vein of the previous month. In late October and November 2003 periods (Fig. 2c), the weather is characterized by variable winds, and northeasterly winds prevail for most of the events. Relatively low winds persist in the middle of the second segment, however the maximum hourly speed of about $20 \mathrm{~m} \mathrm{~s}^{-1}$ is observed in this segment.

\subsection{Sea breezes and events}

The sea breeze is mainly responsible for transferring energy to coastal systems. When the sea breeze is present, wind speeds are usually low $\left(\sim 4 \mathrm{~m} \mathrm{~s}^{-1}\right)$ and directed onshore (southward). The sea breeze begins from early morning at 05:00 a.m. Then the wind direction changes to seaward around $4 \mathrm{pm}$ and decreases $\left(\sim 2 \mathrm{~m} \mathrm{~s}^{-1}\right)$. Although the wind shear stress is usually very small, its effect can be significant when integrated over a large body of water (Dean and Dalrymple, 1991). Figure $2 b$ and $d$, shows the wind stress of the hourly wind data in two segments, estimating following $\mathrm{Wu}$ (1969). In the first section of wind data (first $720 \mathrm{~h}$, Fig. 2b), wind stress is low and does not vary too much in direction, mainly directed to eastward. The last part of the wind record, (Fig. 2d) shows relatively strong wind stress events, which were directed to the eastward as well. Mean and variance values based on hourly and daily filtered wind data (Table 1) reveal that approximately $60 \%$ of the wind energy is attributed to the $1 \mathrm{cpd}$ and higher frequencies in the alongshore direction. However in the cross-shore direction the majority of wind energy (67-83\%) accumulates on $1 \mathrm{cpd}$ and higher frequencies. Daily averaged wind time series for the first segment, and a number of storm events during late summer and early winter, are shown in Fig. 3. The mean sea breeze vectors over one month illustrate a permanent residual wind toward the southeast. Similarly the rest of wind records (Fig. 3c-d) show a lasting southeastward forcing over the study area. As is evident from wind time series, the sea breeze system is present throughout the year and acts as the regular forcing in a similar manner to that of 

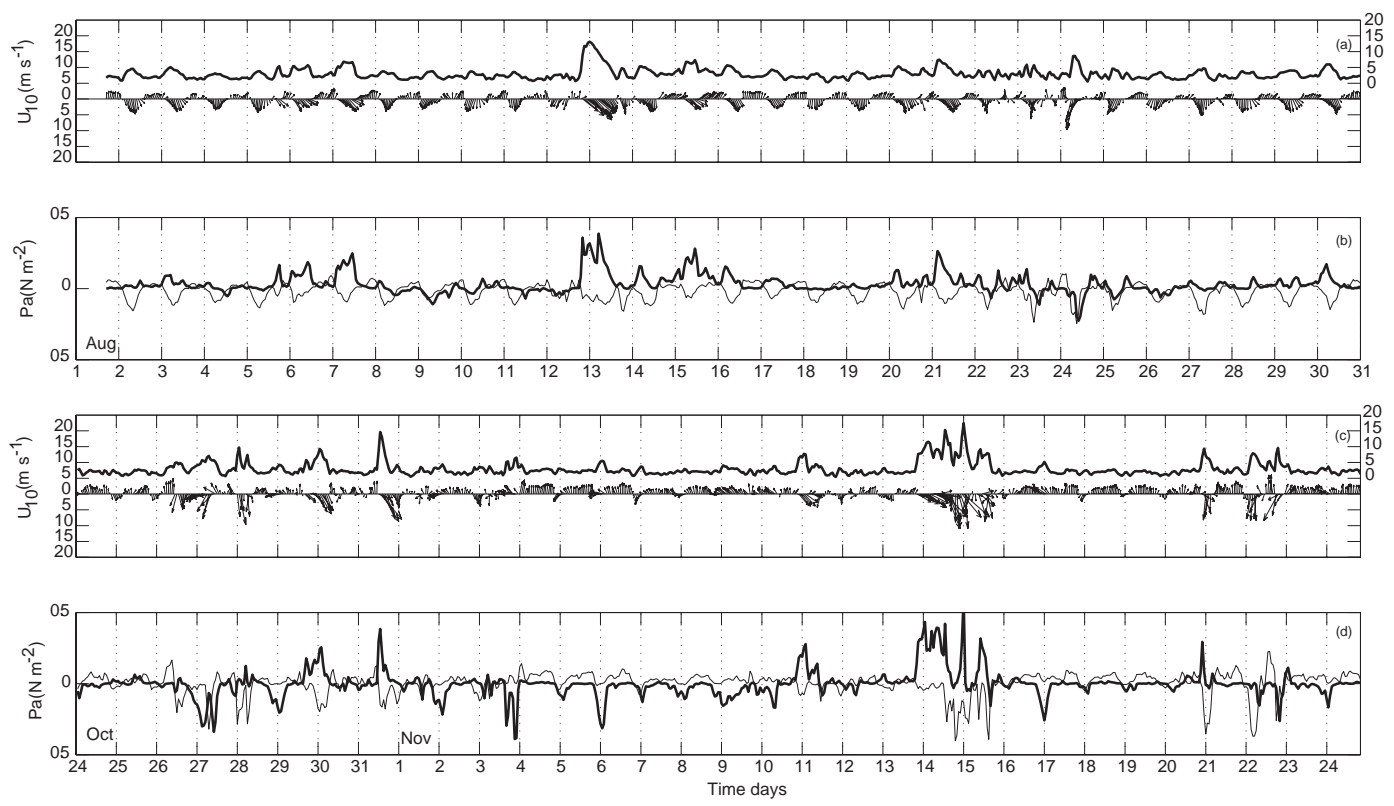

Fig. 2. Wind stick plot and wind stress of hourly filtered wind components data, alongshore ( $348^{\circ} \mathrm{N}$, thick line), and cross-shore $\left(78^{\circ} \mathrm{E}\right.$, thin line). (a) and (b) first segment (720 h covering whole August 2003); (c) and (d) last segment (from $2000 \mathrm{~h}$ of records to the end from 24 October to 24 November 2003).

Table 1. Mean variance and range of wind velocity and wind stress.

\begin{tabular}{|c|c|c|c|c|c|c|c|c|}
\hline \multirow{2}{*}{$\begin{array}{l}\text { Month } \\
\text { Velocity }\end{array}$} & \multicolumn{2}{|c|}{ Mean $\left(\mathrm{m} \mathrm{s}^{-1}\right)$} & \multicolumn{2}{|c|}{ Hourly Variance $\left(\mathrm{m} \mathrm{s}^{-1}\right)^{2}$} & \multicolumn{2}{|c|}{ Daily Variance $\left(\mathrm{m} \mathrm{s}^{-1}\right)^{2}$} & \multicolumn{2}{|c|}{ Range $\left(\mathrm{m} \mathrm{s}^{-1}\right)$} \\
\hline & Alongshore & Cross-shore & Alongshore & Cross-shore & Alongshore & Cross-shore & Alongshore & Cross-shore \\
\hline Aug & 1.203 & -0.771 & 5.15 & 5.45 & 2.42 & 0.61 & 18.58 & 13.21 \\
\hline Sep & 1.227 & -0.501 & 7.13 & 5.64 & 2.86 & 1.08 & 18.46 & 11.34 \\
\hline Oct & -0.023 & -0.057 & 6.73 & 5.71 & 2.89 & 0.95 & 22.46 & 16.99 \\
\hline Nov & -0.13 & 0.49 & 8.32 & 7.08 & 4.18 & 3.55 & 24.38 & 17.44 \\
\hline Stress & \multicolumn{2}{|c|}{ Mean $\times 10^{-3}$} & \multicolumn{2}{|c|}{ Hourly Variance $\times 10^{-3}$} & \multicolumn{2}{|c|}{ Daily Variance $\times 10^{-3}$} & \multicolumn{2}{|c|}{ Range } \\
\hline Aug & 8.6 & -7.8 & 0.759 & 0.388 & 0.350 & 0.111 & 0.362 & 0.173 \\
\hline Sep & 8.7 & -6.7 & 0.886 & 0.367 & 0.367 & 0.126 & 0.258 & 0.131 \\
\hline Oct & -0.6 & -4.3 & 0.7 & 0.6 & 0.227 & 0.081 & 0.495 & 0.320 \\
\hline Nov & 2.5 & -3.6 & 1.8 & 1.1 & 0.710 & 0.524 & 0.72 & 0.339 \\
\hline
\end{tabular}

tides in other regions. Therefore considering the absence of tidal components, it seems that sea breeze provides the regular high frequency forcing in the southern coastal waters of the CS, as the diurnal and semidiurnal tides do elsewhere.

There are some exceptions which could be remarked as storm events. The storm events occur sporadically and last approximately 1 to 2 days, with peak wind speeds of around $15 \mathrm{~m} \mathrm{~s}^{-1}$ in summer and $20 \mathrm{~m} \mathrm{~s}^{-1}$ in winter which mainly are north-westerly. Because it is a closed basin with no outlet, the role of atmospheric circulation in formation of the CS's hydrodynamics regime is particularly important. The southern CS storms were related to the combination of the sea breeze and the first local synoptic weather patterns. On average the probability of such winds in the course of a year is $41 \%$ (Rodionov, 1994). The number of days with storms (wind speed greater than $15 \mathrm{~m} \mathrm{~s}^{-1}$ ) is not frequent and does not exceed 20-30 days per year (Kosarev, 2005).

\subsection{Response of the current to the wind}

Tidal motions bear a negligible contribution in the total current variability in the CS; therefore the flow field should be considered in absence of tidal force. Strong temporal variation and the current field evolution corresponding to variable 

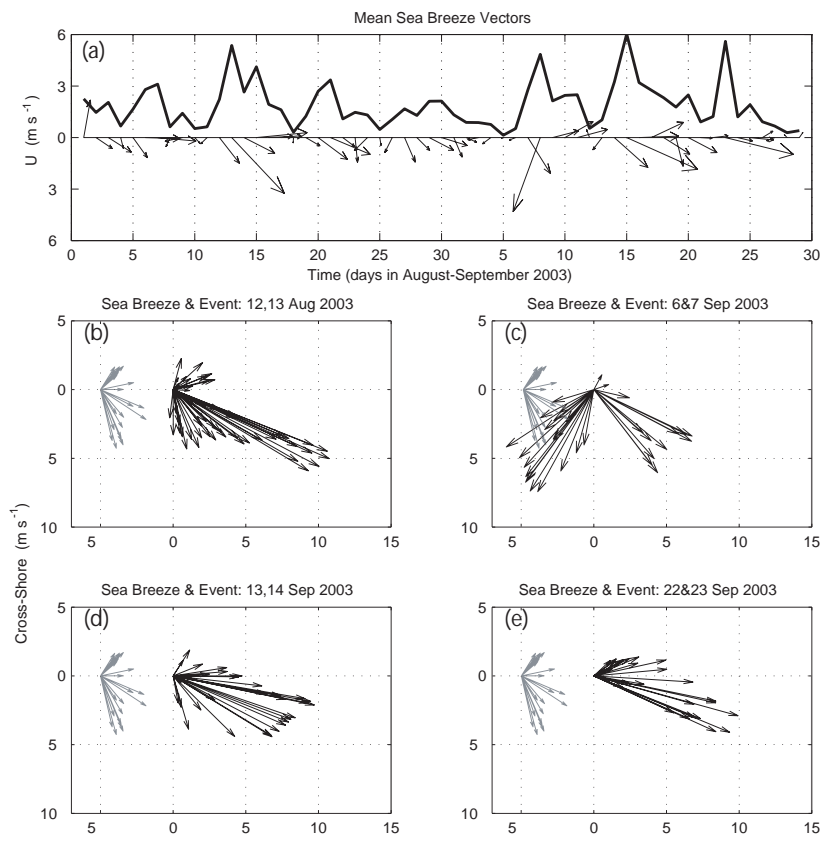

Fig. 3. (a) Mean sea breeze vectors over $25 \mathrm{~h}$ period (1. Sect. of data); (b) storm event: 12, 13 August 2003; (c) storm event: 6, 7 September 2003; (d) storm event: 13, 14 September 2003; (e) storm event: 22, 23 September 2003.

winds during August and September 2003 are represented in Fig. 4, in terms of the hourly wind and the current data. As it is illustrated in this figure, except to the possible influence of the sea breeze on the surface circulation when diurnal variations are dominant, wind forcing is prominent in squally weather conditions. These events occur during the strong winds i.e.; four wind episodes of the Fig. 3, and usually sustain in term of days after wind episodes. The maximum hourly current speed of 50 and $60 \mathrm{~cm} \mathrm{~s}^{-1}$ are recorded respectively on 13-14 August and 14-15 September 2003 subsequent to wind events. Considering the three different layers reveal that the current velocity variations follow almost the same trend throughout the whole water column therefore, flow field shows a barotropic behavior during the recording period. According to Fig. 4 throughout the whole water column the alongshore currents are stronger (almost fourfold) than the cross-shore currents.

Wind and current time series in the alongshore direction show correlation $(r \sim 0.2)$ at one hour time lag at the surface, which maintains the same value to the sea bed (Fig. 5a). This indicated an almost depth independent response of the entire water column to the wind stress in the recording period. In cross-shore direction (Fig. 5b), wind and current demonstrate higher correlation, starting from 0.5 at the surface, decreasing to 0.3 at the bottom. Time lag for the wind forcing decreases from 7 to $1 \mathrm{~h}$ at the first $8 \mathrm{~m}$ surface layer and from $8 \mathrm{~m}$ to bottom current responds to the wind force with $13 \mathrm{~h}$ lag. The maximum correlation between wind and current speeds range from 0.2 to 0.5 during whole measurements suggests that the local wind forcing drive between $4 \%$ and $25 \%$ of the variation in the current velocities, particularly in cross-shore direction. In the alongshore direction the share of local wind force in the variation of the current velocities is negligible. Bondarenko (1994), using the results of field survey in the middle and the northern CS showed that there is no direct relation between wind speed/direction and currents even though in the extreme winds. The measurements along the Iranian coasts have highlighted that although correlation between wind and current are low and strong currents sporadically are evident at calm wind condition, but wind events cause strengthening of the currents. Additionally taking into account the low frequencies (low pass filtered data), the correlation coefficient between wind and current in the alongshore direction increases significantly to 0.5 in almost whole water column. The response of the current to the wind forcing in the alongshore direction demonstrates the same value as hourly data and retains $1 \mathrm{~h}$ from surface to the bottom (Fig. 5c). In terms of the cross-shore direction, a decrease in correlation is distinguishable for the hourly data. The currents respond to the wind force with $10 \mathrm{~h}$ lag at surface which follows by $1 \mathrm{~h}$ lag among the rest of water column (Fig. 5d). This illustrates that the currents and wind force are more correlated in low frequencies in alongshore direction. Moreover it reveals that although in cross-shore, the flow filed is more proportional to diurnal and semidiurnal oscillation of sea breeze, in alongshore direction synoptical weather band is more efficient on flow regime.

\subsection{Wave passing}

Classical understanding of the general circulation of the CS is varied time and again in confrontation with flow field temporal variability on the order of several days. In other words, the characteristics of the flow field with time variability on the order of several days is often very different from the general circulation. In fact, it is possible to find westward current along the Iranian coast in the study area opposite to the general circulation pattern. There are clear indications of the presence of the strong west and eastward coastal currents which were not evidently generated by the local winds, since there was calm wind condition in the most period of the record. Additionally by considering simply the modified Ekman relation for current speed as a function of wind speed, $V_{0}=K U_{10}=\left(\frac{0.0068}{\sqrt{\sin |\varphi|}}\right) U_{10},|\varphi| \geq 10$, where $U_{10}$ is the wind speed at $10 \mathrm{~m}$ above the sea and $V_{0}$ is surface current speed as a function of wind speed (Ralph and Niiler, 2000), it may be concluded that a wind with average $5 \mathrm{~m} \mathrm{~s}^{-1}$ can generate a current with $12 \mathrm{~cm} \mathrm{~s}^{-1}$ velocity over the CS. However along the southeastern coast of the CS currents with $60 \mathrm{~cm} \mathrm{~s}^{-1}$ magnitude are evident at the present of wind with average $5 \mathrm{~m} \mathrm{~s}^{-1}$ speed or during dead calm wind conditions 

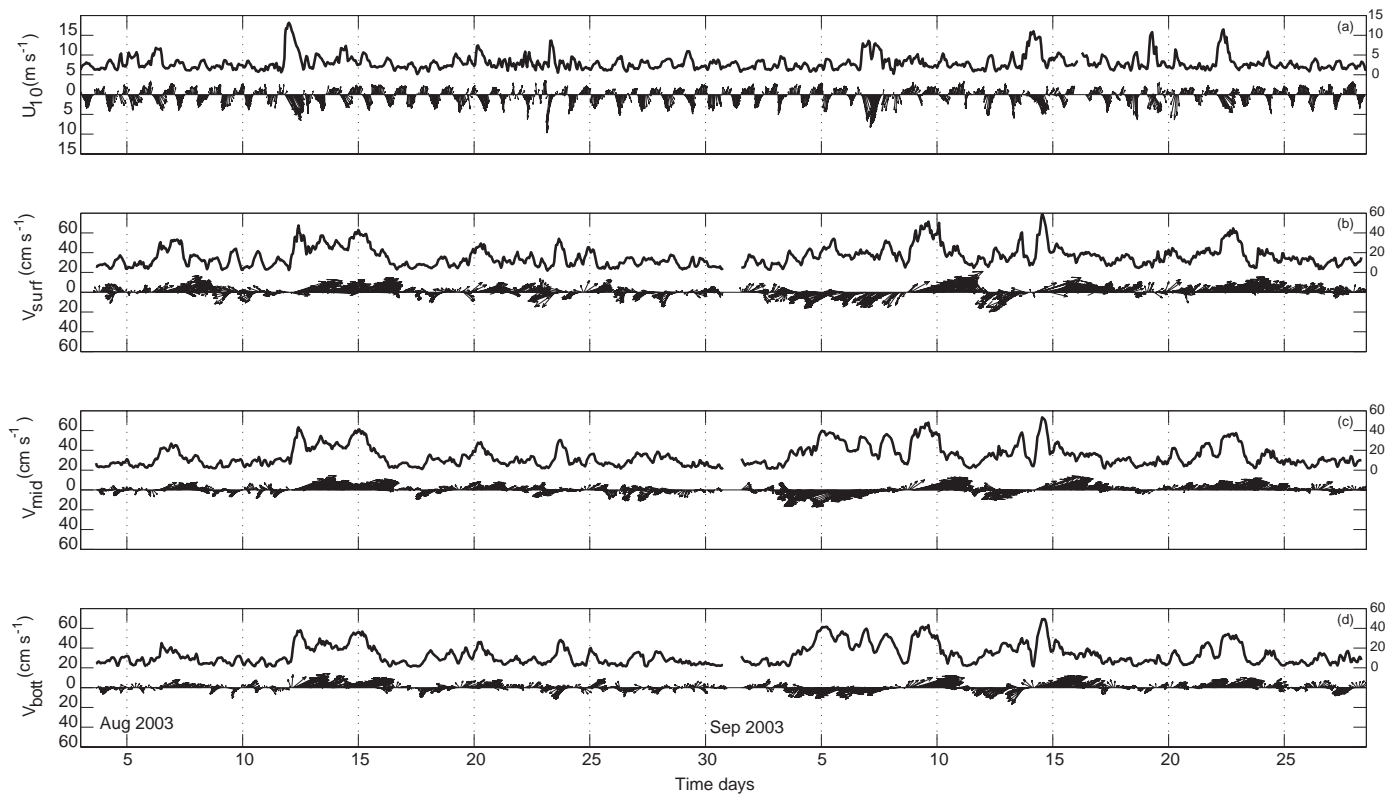

Fig. 4. Current field time series in three different layers respect to the wind. (a) wind speed $\left(U_{10}\right)$; (b) current velocity at surface layer $\left(V_{\text {surf }}\right) ;(\mathbf{c})$ current velocity at middle layer $\left(V_{\text {mid }}\right) ;\left(\right.$ d) current velocity at seabed $\left(V_{\text {bott }}\right)$.

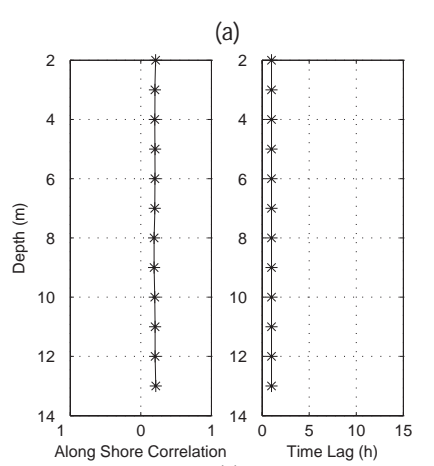

(c)
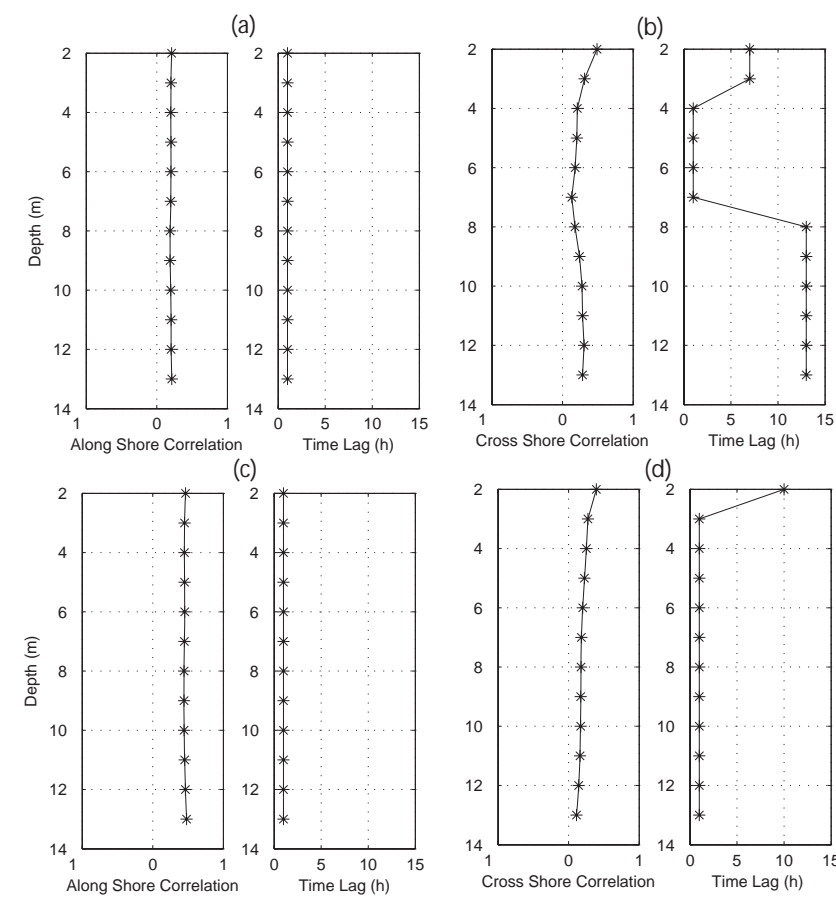

(d)

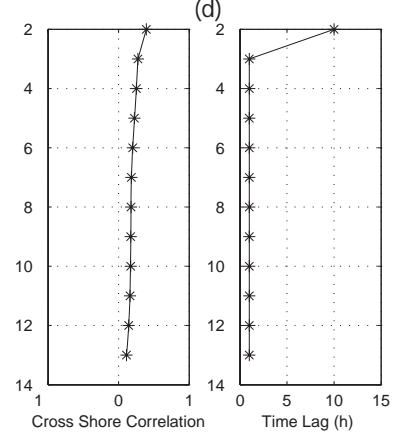

Fig. 5. Time-lagged correlations between wind speed $\left(U_{10}\right)$ and current velocity. The left-side graph in a pair is the correlation coefficient $(r)$, and the right-side graph is the time lag (h). (a) alongshore direction; (b) cross-shore direction; (c) low pass filtered wind and current in alongshore direction; (d) low pass filtered wind and current in cross-shore direction.

(Fig. 4). The occurring of current pulses i.e. on 6-18 September are two consecutive events for which we have rather good evidence of wave passage, based on ADCP data. Current data showed passing waves with approximately 6 days period, which sometimes were reinforced by wind events. In both cases, westward pulses were present at the recording area on 4-8 and 12-14 September (Fig. 4), i.e. at the time of the wave interval and its passing. Then the flow turned toward to the east as could be expected. Thereafter the currents became much less on 18 September, when the pulse became weaker and presumably the waves have passed by. In the ADCP data set, evidence of the transient intensification of the eastward currents may be associated with the passage of the shore-controlled waves. Shore-controlled waves were recorded in the north and middle parts of the CS with $15-20 \mathrm{~cm} \mathrm{~s}^{-1}$ current speed and almost 6 days wave period as well (Bondarenko, 1994). These waves set up the sea level along the coast of the CS and strong currents in the calm or weak wind conditions could be attributed to long waves which originated from other parts of the CS. The passage of waves is especially evident in daily averaged current which illustrated the turning of the current in alongshore direction. Shelf waves set up sea level; therefore the practical way of detecting these waves is processing both currents and sea level data simultaneously. Since neither ADCP nor local tide gauges recorded sea level during the measurement period, there are not any adequate sea level data confirming the wave passage. In brief, it may be concluded that the signals travel with velocities that are much greater than the flow field speed; therefore shelf waves could be the source of the current fluctuations. 


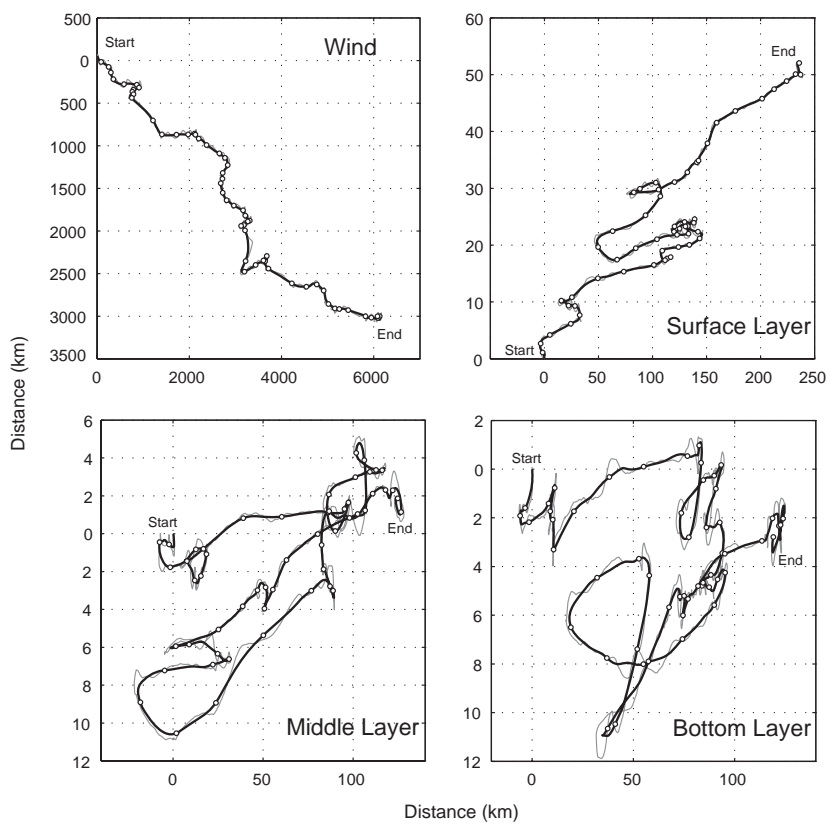

Fig. 6. Progressive vector diagram (PVD) of current and wind components from records obtained at $10 \mathrm{~min}$ intervals and hourly filtered data sets over 57 days measurement period (4 August28 September). Horizontal and vertical axes are alongshore/crossshore coordinates and each of circles on the graphs represent one day.

\subsection{Long term scales}

In order to study the shelf circulation at longer time scales, progressive vector diagrams (PVD) were calculated at selected depths, and the mean vertical current profiles were computed over the whole record. Residual or long-term vector-mean currents are readily apparent in the PVD diagrams, moreover rotational behavior of wave passage signals in horizontal current field are well presented as well (Emery and Thomson, 1998; Pugh, 1987). Figure 6 illustrates the PVDs which have been constructed from successive cumulative values of $u$ (alongshore), and $v$ (cross-shore), components of current and wind from records gathered at 10-min intervals and filtered to one hour over the recording period from August to September 2003 among three distinguished depths. The plotted positions correspond to the horizontal displacement of the water parcel that would occur if the motion in the entire neighboring area of the location of the ADCP was uniform in spatial terms. The PVDs start in the left hand of each panel (4 August) and wind up right hand (28 September). The graphs show that motions at middle and bottom layers more or less are same in terms of scale and the flow field in the shelf is dominated by low frequency variations. The rotational behavior of the shelf motions are well represented in the diagrams. The signatures of passing several days (2-6 days) signals are easily notable among the

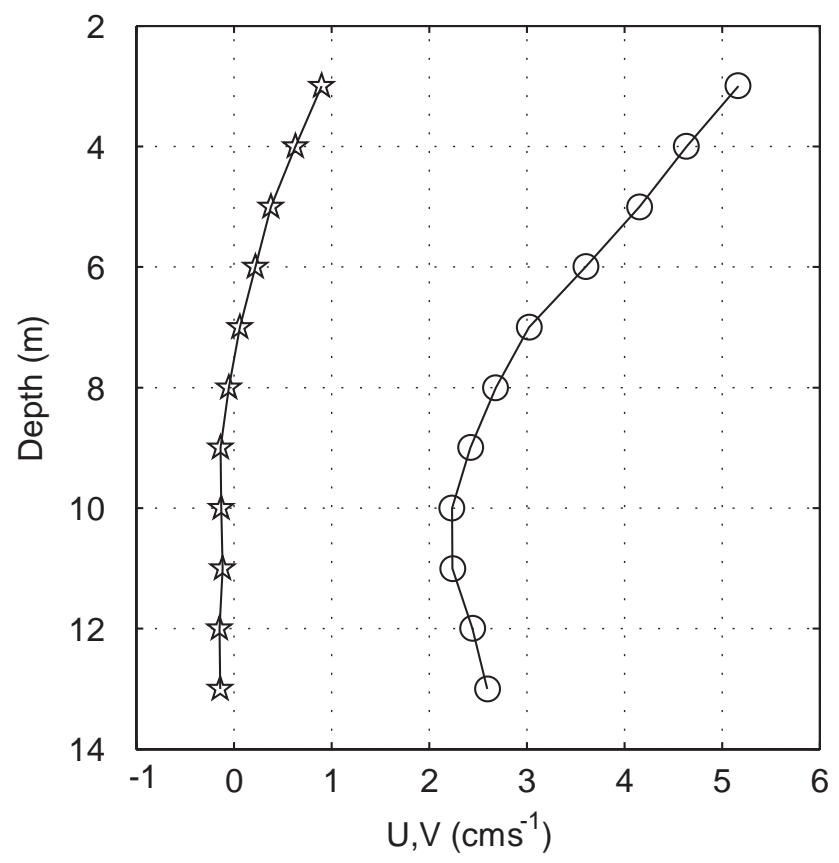

Fig. 7. Mean current components profile, averaged over 57 days measurement period.

water column particularly in the middle and the bottom layers. The PVD of the surface layer is rather decoupled from lower ones and mostly affected by local wind.

Figure 7 shows the mean current components profiles which were averaged over whole period of recording from 4 August to 28 September 2003. Long term along shelf mean flow tends to orient along-isobaths on the continental shelf. Along shelf circulations demonstrate almost one layer structure and eastward motion is prevalent. The amplitude of the mean along shelf current is roughly $4 \mathrm{~cm} \mathrm{~s}^{-1}$ and decreasing with increasing water depth from $5 \mathrm{~cm} \mathrm{~s}^{-1}$ (at surface) to $2 \mathrm{~cm} \mathrm{~s}^{-1}$ (near bottom). The mean cross-shelf current exhibits a robust vertical structure. The upper layer flow is typically offshore and the near bottom mean current is inshore and remarkably constant. Therefore the vertical profile of cross-shelf mean flow shows a two layer structure. Vertical structure of cross-shelf component of flow field on a continental shelf often reveals two layer structures, and our results on the southern continental shelf of the CS are consistent with long-term mooring results on the West Florida Shelf (Weisberg et al., 2009). The vertical structure of the mean current components demonstrates the displacement of the entire water column eastward which agrees in principal with mean sea breeze and the CS classical circulation patterns inside the study area. Therefore despite the clear indications of the presence of the strong westward current pulses which are not evidently could be attributed to the local winds, the long-term displacements of the water column follows the general circulation pattern in the southern CS. 


\subsection{Frequency domain}

Spectral analyses were performed on the current and wind time series, which may vary due to the influence of local and remote winds, horizontal pressure gradient, etc. Autospectra are presented for ADCP data sets at bin $12(1 \mathrm{~m}$, surface layer), bin 6 (7 m, middle layer) and bin 1 (13 m, bottom layer) and wind data for both alongshore and crossshore components. According to Fig. 8, prevailing of the low-frequency signals in the current field during August and September 2003, are evident. Concurrently the current field contained the frequencies which are related to the sea breeze regime. The dominant peaks are in the low-frequency band at synoptic time scale of the order of several days. The alongshore and cross-shore current spectra show roughly a similar amount of energy at the high frequencies $(>0.08 \mathrm{cph})$, while the semidiurnal $(\sim 0.08 \mathrm{cph})$ and diurnal $(\sim 0.04)$ frequencies are shown mainly on the cross-shore spectrum (north-south current in the southern CS). The auto-spectra of different layers show peak alongshore energy in the low frequencies synoptic band, while peak cross-shore energy occurs in the diurnal and semidiurnal frequencies. According to Fig. 8, crossshore variability seems to be more intense near the surface layers. Therefore, diurnal and semi-diurnal peaks are much more evident in surface layer in comparison with the deeper ones. Consequently by descending in depth from the surface layer to the bottom, diminishing of the semidiurnal peak is evident. Overall, it is clear from spectral density that upper bins show relatively more energy among all frequency bands compared to the bottom layers.

As the auto-spectra suggests, there are basically two modes of motion at this site of the southern CS: (1) the motion in the diurnal and semidiurnal bands (attributed to sea breeze) which is generally dominated in cross-shore direction, and (2) the motion in the synoptic band that is mostly pronounced in alongshore direction. In general lowfrequency $(<0.02 \mathrm{cph}$; i.e., with periods $>50 \mathrm{~h})$, diurnal $(\sim 0.04 \mathrm{cph})$ and semi-diurnal $(\sim 0.08 \mathrm{cph})$, oscillations account for most of the variance. Under actual conditions in the surface sea layer, wind induced currents play a rather significant role. Our data show in the synoptic range of the current variability oscillations with periods from $2-3$ days to 1-3 weeks prevail in the CS, that are reported previously by Baidin and Kosarev (1986). Based on Brink (1991), these oscillations are related to the synoptic variability of the direct wind impact and to coastal trapped waves which are supported by present study as well. In the higher frequency range, current variability is dominated by internal gravity waves and seiches (Tuzhilkin and Kosarev, 2005).

To shed some light on flow field characteristic in the study area, rotary power spectra of hourly filtered current data in three layers and the wind data are presented in Fig. 9. According to the energy levels, variability seems to be more intense near the surface and this layer shows the best response to the sea breeze diurnal and semi-diurnal oscillations. In
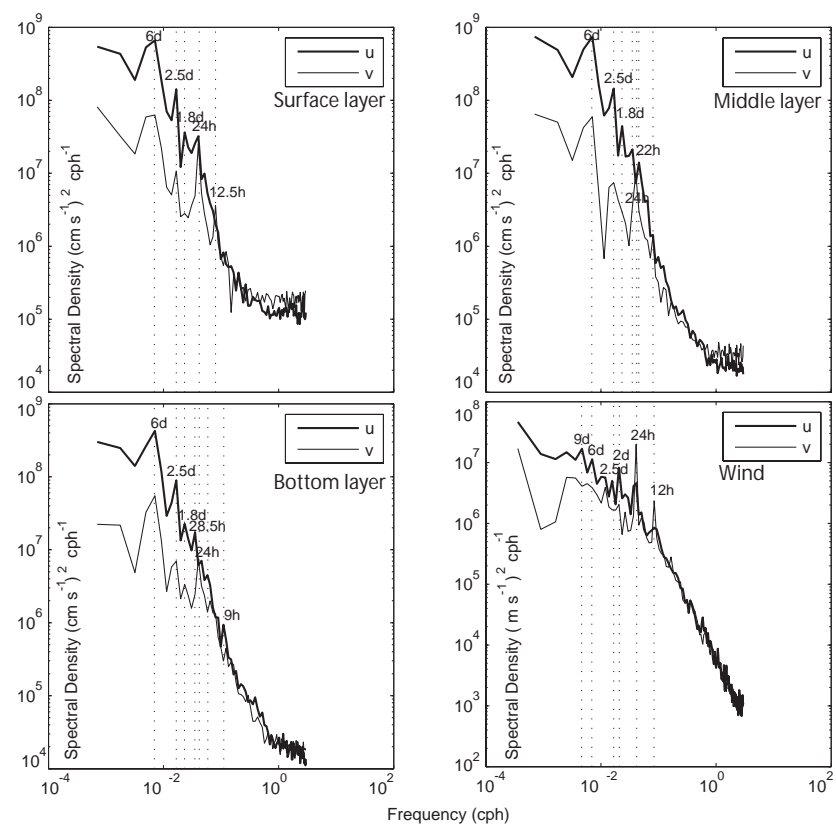

Fig. 8. Power spectral density of the alongshore $\left(348^{\circ} \mathrm{N}\right.$, thick line), and cross-shore $\left(78^{\circ} \mathrm{E}\right.$, thin line) components of the wind and current based on hourly filtered data sets for whole recording period during August and September 2003.

terms of the currents, diurnal and semi-diurnal bands are manifested in merely positive sense of rotation, showing that sea breeze forces anti-clockwise rotation. Wind rotary spectra, reveals that cyclonic rotation in diurnal and semi-diurnal bands is dominant in sea breeze as well. During the recording period, the $0.0156 \mathrm{cph}(\sim 2.5$ days $)$ signal is distributed almost symmetrically around the zero frequency, illustrating that the motion is almost rectilinear at this frequency. Lower frequency signals ( $\sim 5$ days and more periods) at the surface layer behave similar to the wind, so clockwise rotation is slightly stronger than cyclonic one. Conversely, in the middle layers signals distributions are symmetrical and in the deeper layers, strengthening of the positive sense of rotation is evident. All above findings indicate a prevalence of the rotational motion over the rectilinear ones, particularly in diurnal and semi-diurnal bands.

The presence of significant diurnal oscillation in the wind provide a favorable condition for the generation of the inertial oscillation (Jossia Joseph et al., 2007), which is quite true for the study area. Moreover, a strong thermocline which is located between $20 \mathrm{~m}$ and $50 \mathrm{~m}$ depths in warmer phase with $15^{\circ} \mathrm{C}$ temperature gradient (Zaker et al., 2007), provides favorable condition for forming of inertial motions in the study area. In these circumstances inertial oscillations may persist for several days after their generation and be advected to the other regions. Therefore resembling the middle part of the CS, which inertial oscillation with a period of $17.5 \mathrm{~h}$ was recorded (Bondarenko, 1994), we expected to 


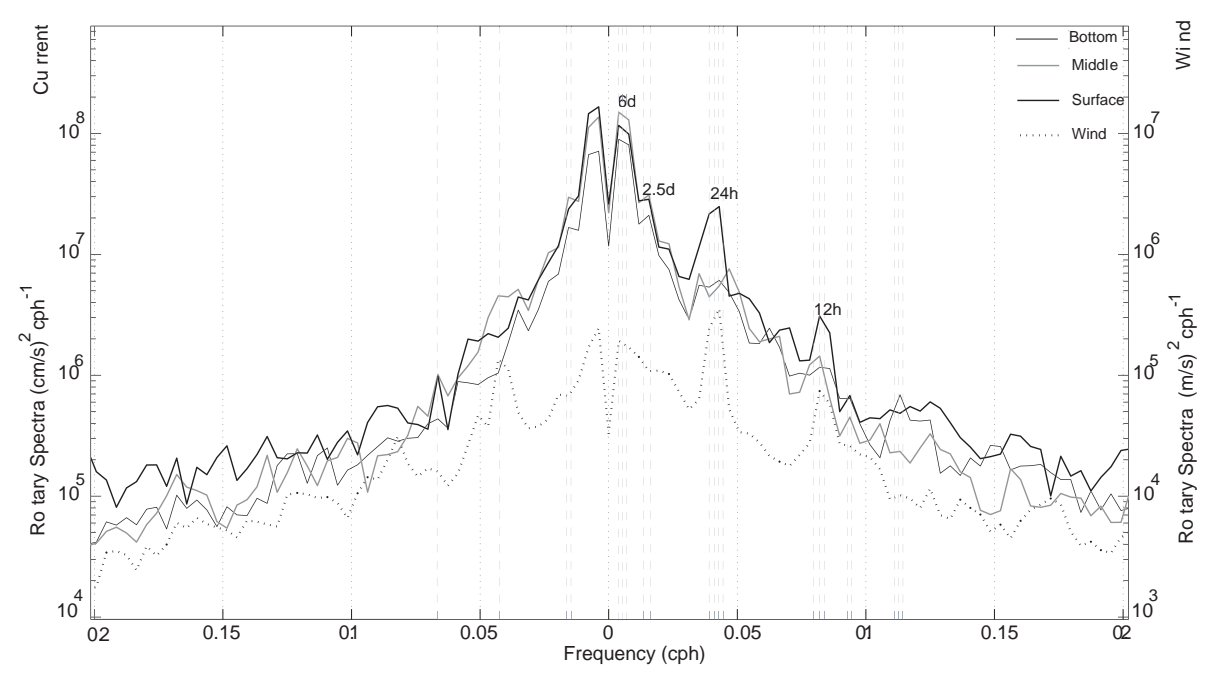

Fig. 9. Two-sided rotary spectrum of hourly filtered current components at three layers (surface, middle and bottom layers which have been shown as thick, dotted and thin lines, respectively) and wind components (bold dotted line) for whole recording period during August and September 2003.

come across the inertial currents with a period of oscillation of about $19.5 \mathrm{~h}(\sim 0.05 \mathrm{cph})$ in negative sense of rotation. But considering the proximity of the recording station to the coastal boundary, inertial signals are not manifested in the rotary power spectra.

\subsection{Low frequency motion}

The motion in the low frequency synoptic band contains most of the energy of current fluctuations off FB (see Fig. 7). These low frequency oscillations particularly in the shelf wave band seem to be a substantial part of the flow field in the CS, since they were observed along the whole coast of the CS (Bondarenko, 1994), with amplitudes ranging between 15 and $20 \mathrm{~cm} \mathrm{~s}^{-1}$. To facilitate relation between the low frequency motion and wind, the vertical structure for the coastal motion and wind is shown in the low frequency band in Fig. 10. The time series of the current amplitudes depict temporal variations, which follow resemblance trend with low pass component of the wind in alongshore direction. However in cross-shore direction, as it was expected, they do not show the same correspondence. Figure 10 demonstrates the coexistence of up and downward propagating phases of low frequency motions. The current exhibits variations mostly with the time scale about 1.8, 2.5 and 6 days that is centered at the period of about 2.5 days. This motion is a pure barotropic one according to both the spectrum (Fig. 8) and the structure of the corresponding vertical distribution that revealed in the time series. However, these fluctuations are quasi-stationary since they are well pronounced in the entire measurement period. To achieve a better understanding of low frequency motions, the current data sets were vertically averaged and the resulted barotropic
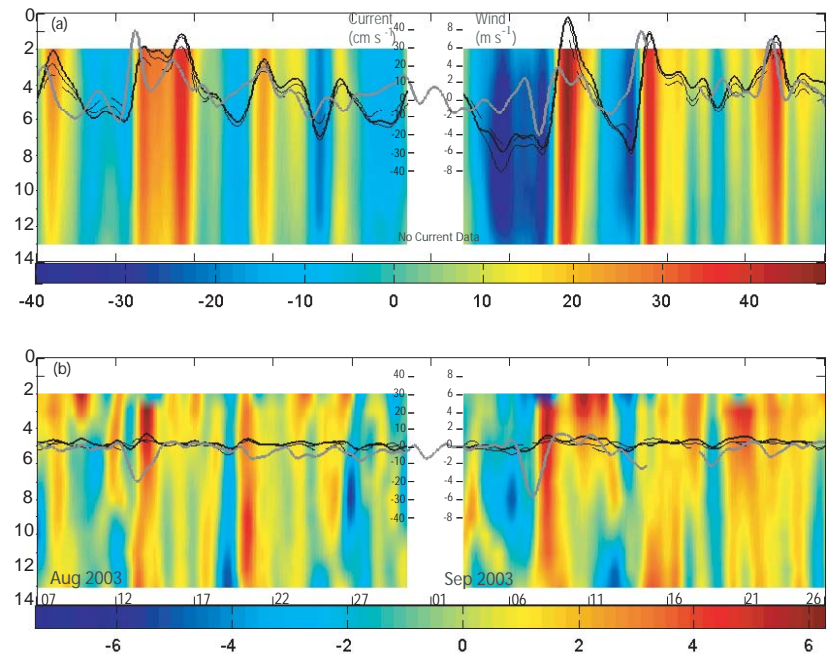

Fig. 10. Low frequency wind (thick grey line) and current across the water column and at distinguished three layers: surface, middle and bottom layers (have been shown as thick, thin and dashed lines, respectively) time series. (a) Alongshore directions; (b) cross-shore direction.

current was analyzed with rotary spectral analysis that has not been shown here. The results confirmed that while diurnal and semi-diurnal motions were significantly rotated anticlockwise, the barotropic motion in the shelf wave (low frequency) band and longer scales tended to be linear polarized. 


\section{Concluding remarks}

In this work, the ADCP and wind data sets have been analyzed to study the shelf circulation and flow field off Feridoon-kenar Bay (FB) in the southern part of the CS. Data sets were obtained during the Physical Oceanography Studies of Southern Coastal Waters of the Caspian Sea Project, accomplished by Iranian National Center for Oceanography (INCO), from August to September 2003. Field data were collected along the shallow, wind-dominated coastal waters off FB from late summer to early autumn when the water column is stratified and vertically quasi-homogeneous, respectively. The data sets have been separated into three timedependent terms: low frequency signals, diurnal and semidiurnal bands, and the high frequency parts. Additionally the current field has been divided into three layers: surface, middle and bottom. Based on the field data and analyses, it was concluded that:

- Wind sea breeze system is one of the forcing mechanisms that controls the water column dynamics in the southern CS. Wind force covers rather quickly water column of the continental shelf and promoting development of current from the surface to the bottom in one direction. The sea breeze dominates the energy input in to the coastal system. Based on the recorded data, most of the wind energy is attributed to the low frequencies in alongshore direction. Mean sea breeze vectors illustrates the existence of lasting south-east ward forcing system over the study area. It is evident that the sea breeze system is present throughout the year and acts as the regular forcing in a similar manner to that of tides in other regions.

- Flow field variation across the whole water column is showed a barotropic behavior and wind stress produces a similar response across the water column. Alongshore currents and wind are correlated to some extent in low frequencies while in cross-shore direction, the maximum correlation between currents and wind was occurred in $1 \mathrm{cpd}$ and higher frequencies. Therefore, although in cross shelf the flow field is proportional to diurnal and semi-diurnal bands and higher frequency oscillations, the synoptical weather band seems to be more efficient in alongshore flow regime.

- While long-term displacements of the current components follow the classical circulation pattern in the south $\mathrm{CS}$, the characteristics of the flow field with time variability on the order of several days is often very different. In fact, it is possible to find west ward current along the Iranian coast in the study area opposite to the general circulation pattern. There are clear indications of the presence of the strong west and east ward coastal currents which were not evidently generated by the local winds, since there was calm wind condition in the most case of the recording span. Our analyses showed that the strong quasi-stationary currents and the signature of passing several days (2-6 days period) signals in wave form are distinguishable in the region. It seems that investigating the local wind is not sufficient in order to completely understand the southern CS flow field. In fact these current pulses in the study area could be explained by shelf-controlled waves. Therefore it could be postulated that the current field in the south $\mathrm{CS}$, is under the influence of the long-period wave currents and remotely forced winds. In other words, generation of strong currents in absence of the wind could be related to shore-controlled long-waves which are remotely formed and forced in the other parts of the CS and travel across the shelf in the southern CS. Moreover remotely generated long-period pulses are reinforced and or suppressed by local winds. Most probably strong currents around $60 \mathrm{~cm} / \mathrm{s}$ occur by superposing of remotely and local forced motions.

These findings confirm that in the shallow coastal waters off FB, two modes of motion could be distinguishable: first, high frequency motions ( $0.042 \mathrm{cph}$ and higher), are mainly proportional to the sea breeze system and dominant in crossshore direction. Second, low frequency motions located at synoptic weather bands in alongshore orientation. The low frequency motions are related to synoptic variability of the direct and remote wind impacts and shelf-controlled longperiod wave currents. We think the conventional concept (direct wind-induced currents are dominate in the closed systems), is not sufficient to illustrate properly the complicate flow field in the southern part of the CS. Apparently the longperiod wave currents, whose velocities are much greater than the direct wind-driven ones, are responsible for the major part of flow field variations. All this shows the need for detailed theoretical studies (coupled with field surveys and numerical models) of the flow field in the southern CS.

Acknowledgements. We thank the Department of Physical Oceanography of INCO for supporting field survey and providing current and wind data. Additionally authors acknowledge H. Alizadeh for his contribution in translating a number of Russian references, and Mike Kosro for editing and improving the manuscript and also Yonggang Lui due to his valuable contribution.

Edited by: M. Kosro 


\section{References}

Baidin, S. S. and Kosarev, A. N.: The Caspian Sea, Hydrology and Hydrochemistry, Nauka Moscow, Russia, 1986.

Beardsley, R. C., Limeburner, R., and Rosenfeld, L. K.: Introduction to the CODE-2 moored array and large-scale data report, edited by: Limeburner, R., Woods Hole Oceanographic Institution, 1985.

Bondarenko, A. L.: Currents of the Caspian Sea and formation of salinity of the waters of the north part of the Caspian Sea, Nauka, Moscow, Russia, 1993.

Bondarenko, A. L.: Natural Investigation of the Caspian Sea Currents, Russian Academy of Science, Water Problems Institute, 1994.

Brink, K. H.: Coastal-Trapped Waves and Wind-Driven Currents over the Continental Shelf, Ann. Rev. Fluid Mech., 23, 389-412, 1991.

Dean, R. G. and Dalrymple, R. A.: Water Wave Mechanics for Engineers and Scientists, World Scientific Publishing Co. Pte. Ltd., 1991.

Emery, W. J. and Thomson, R. E.: Data Analysis Methods in Physical Oceanography, Elsevier Science B. V., Amsterdam, The Netherlands, 1998.

Filimonova, M. and Trubetskova, M.: Calculation of evaporation from the Caspian Sea surface, 9th ISSH SEMINAR on Stochastic Hydraulics, De Vereeniging, Nijmegen, The Netherlands, 2005.

Flagg, C. N., Vennersch, J. A., and Beardsley, R. C.: 1974 M. I. T. New England Shelf dynamics experiment (March, 1974) Data Report Part II: The moored array: M. I. T. Report 76-1, Massachusetts Institute of Technology, Cambridge, MA, USA, 1976.

Free, M., Angell, J. K., Durre, I., Lanzante, J., Peterson, T. C., and Seidel, D. J.: Using First Differences to reduce inhomogeneity in radiosonde temperature datasets, J. Climate, 17, 4171-4179, 2004.

Froehlich, K., Rozanskib, A. K., Povinecc, P., Oregionic, B., and Gastaud, J.: Isotope studies in the Caspian Sea, Sci. Total Environ., 237-238, 419-427, 1999.

Ismailova, B. B.: Geoinformation modeling of wind-induced surges on the northern-eastern Caspian Sea, Math. Comput. Simulat., 67, 371-377, 2004.

Jossia Joseph, K., Balchand, A. N., Hareeshkumar, P. V., and Rajish, G.: Inertial oscillation forced by the September 1997 cyclone in the Bay of Bengal, Curr. Sci. India, 92, 790-794, 2007.

Klevtsova, N. D.: Sea current regime near east coast of the middle and south Caspian basins, Proceedings of Hydrometeoobservatory of Baku, Baku, Azerbaijan, 1967.

Korotenko, K. A., Mamedov, R. M., and Mooers, C. N. K.: Prediction of the dispersal of oil transport in the Caspian Sea resulting from a continuous release, Spill Sci. Technol. B., 6, 323-339, 2000.

Kosarev, A.: The Caspian Sea, Water structure and dynamics, Moscow, Russia, 1990.

Kosarev, A.: Physico-Geographical Condition of the Caspian Sea, in: The Caspian Sea Environment, edited by: Kostianoy, A. and Kosarev, A., Springer-Verlag, Berlin, Heidelberg, Germany, 2005.
Kovačević, V., Gačić, M., Mancero Mosquera, I., Mazzoldi, A., and Marinetti, S.: HF radar observations in the northern Adriatic: surface current field in front of the Venetian Lagoon, J. Mar. Syst., 51, 95-122, 2004.

Madat-Zade, A. A.: Principal types of atmospheric processes determining wind field over the Caspian Sea, Proceedings of the Oceanological Commission of the Academy of science of the USSR, 1959.

Mofidi, A., Zarrin, A., and Janbaz Ghobadi, G.: Determining the synoptic pattern of autumn heavy and extreme precipitations on the southern coast of the Caspian Sea, J. Earth Space Phys., 33(30), 131-154, 2008.

Peeters, F., Kipfer, R., Achermann, D., Hofer, M., AeschbachHertig, M., Beyerle, U., Imboden, D. M., Rozanski, K., and Fröhlich, K.: Analysis of deep-water exchange in the Caspian Sea based on environmental tracers, Deep-Sea Res. Pt. I, 47, 621-654, 2000.

Peterson, T., Karl, T., Jamason, P., Knight, R., and Easterling, D.: First difference method: Maximizing station density for the calculation of long-term global temperature change, J. Geophys. Res., 103, 25967-25974, 1998.

Pugh, D. T.: Tides, Surges and Mean Sea-Level, John Wiley \& Sons, Chichester, UK, 1987.

Ralph, E. A. and Niiler, P. P.: Wind-driven currents in the tropical Pacific, J. Phys. Oceanogr., 29, 2121-2129, 2000.

Rodionov, S. N.: Global and regional climate interaction: the Caspian Sea experience, Kluwer Academic, Dordrecht, London, UK, 1994.

Sur, H. L., Özsoy, E., and Ibrayev, R.: Satellite - Derived Flow Characteristics of the Caspian Sea, in: Satellites, Oceanography and Society, edited by: Halpern, D., Elsevier Oceanography Series, Elsevier, 2000.

Terziev, F. S., Kosarev, A., and Kerimov, A. A.: The Seas of the USSR. Hydrometeorology and Hydrochemistry of the Seas, Vol. VI: The Caspian Sea, Issue 1: Hydrometeorological Conditions, Gidrometeoizdat, St. Petersburg, Russia, 1992.

Trukhchev, D., Kosarev, A., Ivanova, D., and Tuzhilkin, V.: Numerical analysis of the general circulation in the Caspian Sea, Comptes Rendus de l'Academie Bulgare des Sciences, Sofia, Bulgaria, 48, 35-38, 1995.

Tuzhilkin, V. and Kosarev, A.: Thermohaline Structure and General Circulation of the Caspian Sea Waters. in: The Caspian Sea environment, edited by: Kostianoy, A. and Kosarev, A., SpringerVerlag, Berlin, Heidelberg, Germany, 2005.

Tuzhilkin, V., Kosarev, A. N., Trukhchev, D. I., and Ivanov, V. P.: Seasonal features of general circulation in the Caspian deep water part, Meteorology and Hydrology I, 91-99, 1997.

Vali-Khodjeini, A.: Hydrology of the Caspian Sea and its problems. Proceedings of the Vienna Symposium, IAHS Publication, 1994.

Weisberg, R. H., Liu, Y., Mayer, D. A.: West Florida Shelf mean circulation observed with long-term moorings, Geophys. Res. Lett., 36(1-6), L19610, doi:10.1029/2009GL040028, 2009.

Wu, J.: Wind Stress and Surface Roughness at Sea Interface, J. Geophys. Res., 74, 444-453, 1969.

Zaker, N. H., Ghaffari, P., and Jamshidi, S.: Physical Study of the Southern Coastal Waters of the Caspian Sea, off Babolsar, Mazandaran in Iran, J. Coastal R., Special Issue, 50, 564-569, 2007. 